\title{
RESEARCH
}

Open Access

\section{The role of the natural and built environment in cycling duration in the Netherlands}

\author{
Jie Gao ${ }^{1 *} \mathbb{D}$, Carlijn B. M. Kamphuis ${ }^{2}$, Martin Dijst ${ }^{1}$ and Marco Helbich ${ }^{1}$
}

\begin{abstract}
Background: Cycling for transportation has the potential to contribute to an increase in people's physical activity levels. A growing body of evidence links the natural and the built environment to cycling. Whereas previous studies were mostly done within one city or one region, the present study covers the whole of the Netherlands, allowing an investigation of whether associations between environmental characteristics and cycling are context-specific. The study examines the extent to which objectively measured natural and built environment characteristics contribute to cycling duration in the Netherlands, as well as the differential effect of environmental characteristics on cycling duration by municipality size.

Methods: Our sample from the Dutch National Travel Survey 2010-2014 comprised 110,027 people aged 20-89 years, residing in 3163 four-digit postal code areas, nested within 387 municipalities across the whole of the Netherlands. Multilevel Tobit regression models were fitted to assess the associations between the natural and the built environment with average daily cycling duration (in minutes), while adjusting for individual and household characteristics. Interaction effects of natural and built environment characteristics and municipality size on cycling duration were also investigated.
\end{abstract}

Results: Higher address density, more bus stops, and shorter distance from home to the nearest train station were positively related to cycling duration. Respondents were more likely to cycle on days with higher temperatures, less wind, and less precipitation. Interaction tests showed that increased street density and address density were less cycling-promotive in small urban areas compared to medium or large cities. On the other hand, the positive association between number of bus stops and cycling duration was weaker in the largest and medium-sized cities compared to small urban and rural areas.

Conclusions: Interactions suggest that relations between environmental characteristics and cycling duration are context-specific (i.e., dependent on circumstances that differ between highly urbanized and less urbanized areas). Our findings need to be replicated in other countries to gain more insight into the interplay between environmental factors and municipality size.

Keywords: Cycling, Natural and built environment, Municipality, Multilevel regression model, The Netherlands

\footnotetext{
*Correspondence: j.gao1@uu.nl

${ }^{1}$ Department of Human Geography and Spatial Planning, Faculty of Geosciences, Utrecht University, Princetonlaan 8a, 3584 CB Utrecht, The Netherlands

Full list of author information is available at the end of the article
}

(c) The Author(s). 2018 Open Access This article is distributed under the terms of the Creative Commons Attribution 4.0 International License (http://creativecommons.org/licenses/by/4.0/), which permits unrestricted use, distribution, and reproduction in any medium, provided you give appropriate credit to the original author(s) and the source, provide a link to the Creative Commons license, and indicate if changes were made. The Creative Commons Public Domain Dedication waiver (http://creativecommons.org/publicdomain/zero/1.0/) applies to the data made available in this article, unless otherwise stated. 


\section{Background}

Physical activity provides a range of health benefits and reduces the risks of chronic diseases, such as obesity, diabetes, and high blood pressure [1, 2]. Cycling for transportation has the potential to contribute to an increase in people's physical activity levels [3], and is an environmentally sustainable mode of transportation [4]. As a consequence, national and local governments are eager to promote cycling in order to obtain the associated health benefits [5-7]. Large variations exist in bicycle use between countries. It was estimated that bicycling accounts for about $1-2 \%$ of all trips in North America and Australia [8], which is a much lower percentage than in northern Europe: Figures range from a high of $27 \%$ in the Netherlands (all ages) to $18 \%$ in Denmark (10-84 years) and around 10\% in Finland (6 + years), Germany (all ages), and Belgium (6+ years) $[9,10]$. However, bicycle use varies not only between countries, but also between areas and municipalities within a country [11]. Although $27 \%$ of all trips are made by bicycle in the Netherlands $[12,13]$, there are substantial variations in the share of short-distance (i.e., up to $7.5 \mathrm{~km}$ ) bicycle trips between Dutch municipalities; for example, the share is $17 \%$ in Heerlen ${ }^{1}$ and nearly $50 \%$ in Groningen ${ }^{2}$ [14]. These large variations between municipalities possibly correspond to variations in environmental characteristics, but few studies have examined this $[6,15]$.

Studies have shown that cycling duration is related not only to individual attributes (e.g., sociodemographic characteristics), but also to the environment in which people live and move around [16-18]. There is empirical evidence that population and address density, land use, building diversity, and urban design (e.g., street network configurations) affect cycling levels [19-23]. The effects of population density on cycling behavior might often be indirect. A higher population density is often required to support a greater diversity in local destinations and to reduce distances between places. Higher population density is found to relate to a higher likelihood of bicycle use [7, 24]. Similarly, land use diversity, characterized by a mixed land-use, brings origins and destinations closer together and shortens trip distances [24-26]. Mixed-use neighborhoods make trips by bike more convenient [27]. Regarding urban design, a cycling friendly street network and infrastructure characteristics may increase the accessibility of different destinations by bicycle. Studies suggest that people who live in neighborhoods that have been designed to be cycling friendly, which are characterized by higher levels of street connectivity, may increase the likelihood of bicycle use [19, 27-30].

In addition to the built environment factors, natural environment characteristics are also thought to be important
$[4,29]$. Various studies have investigated the effects of weather on daily bicycle use [31-33], and found that sunshine and warm weather increased the probability of commute cycling, and that cold weather and windy weather were inversely associated with cycling [34]. Weather may influence the relation between environmental determinants and bicycle use [35]. Since cyclists are directly exposed to the elements, high or low temperatures and heavy precipitation may make cyclists hesitant to expose themselves for too long. Therefore, the effects of weather may be inherently related to cycling duration.

Even though these studies contributed significantly to our understanding of how natural and built environments are related to cycling behavior, findings appear to be inconsistent. For example, higher residential densities are related to higher shares of non-motorized travel (e.g., cycling) [36, 37], while another study concluded that residential densities do not have a large influence on bicycle use [38]. Additionally, while green space was reported to be positively related to cycling $[39,40]$, others found no associations [25]. One major concern is that although it has been found that factors promoting or impeding cycling show significant spatial variation, most previous studies were based on the assumption that the relationship between individuals as well as environmental factors and cycling is spatially constant (i.e., built environment variables influence travel behavior in a similar manner everywhere) [41, 42]. However, the associations between cycling behavior and the natural and built environment characteristics might vary across areas $[41,42]$. In addition, previous studies were mostly conducted within only one city or one region, whereas investigations covering a larger area (e.g., a whole country or several countries such as done in the study of [6]) are likely to result in more variation in environmental characteristics. More advanced statistical analyses, including interaction effects, may also uncover complex relationships between the environmental determinants and cycling behavior. For example, it is necessary to examine how the relationships between natural and built environmental determinants and cycling behavior may vary across areas, especially according to the urbanization level, as a previous review study has suggested [43]. This can offer a better insight into the role of natural and built environment characteristics for cycling across municipalities.

It is well-established that cycling behavior (e.g. duration and frequency) vary depending on people's sociodemographic characteristics (e.g., age, gender, education level) [44-47] and across geographic scales [41, 48]. Although sociodemographic characteristics have been shown to be more strongly correlated with travel behavior than environmental factors [49, 50], urban form (e.g. municipality size) also seems to 
explain some variations in travel behavior. From a theoretical perspective, the socio-ecological model suggests a human-environment interplay [18]. It is therefore, necessary to examine urban form characteristics such as municipality size as a potential moderator of the relationship between natural and built environmental characteristics and cycling behavior. Such interactions may help to clarify inconsistent associations between environment and cycling.

To sum up, results concerning the associations between cycling duration and the natural and the built environment are contradictory [51], research on how natural and built environment characteristics relate to between-area variation in cycling duration is inconclusive, and whether the associations between these environment characteristics and cycling duration differ across settings (e.g., whether they are moderated by municipality size) [6] is unknown. The aim of the present research was to investigate the extent to which objectively measured natural and built environment characteristics contribute to differences in cycling (for all purposes) duration in adults (20-89 years) between 4-digit postal code areas (PC4 areas) and between municipalities across the Netherlands, and to explore interaction effects between environment characteristics and municipality size on cycling. We hypothesized that the associations between cycling duration and natural and the built environment characteristics would vary across areas and be potentially moderated by municipality size. To our knowledge, no previous study has investigated the hypothesized moderating effect of municipality size on the association between natural and the built environment and cycling.

\section{Methods \\ Study design}

This study was cross-sectional for the period 2010-2014 and dealt with adults aged 20-89 years residing in 3163 postal code areas (i.e., PC4 level) nested in 387 municipalities across the Netherlands. Figure 1 summarizes the underlying conceptual model.

\section{Travel survey data}

Data were obtained from the Dutch National Travel Survey (NTS) for the period 2010-2014. The NTS is a continuous survey of approximately 40,000 individuals conducted annually by Statistics Netherlands [52]. Respondents report their transportation behavior by means of a travel diary for 1 day. For each trip, travel data include transportation modes, place of origin and destination, time of departure and arrival, and travel purpose. The sample is representative of the Dutch population. The respondents' residential locations were geocoded on a PC4 level, which allowed data linkages with attributes describing the residential environment. Participants without postal code information $(n=708)$ were excluded from the research. This resulted in a final sample of 110,027 people aged 20-89 years, residing in 3163 PC4 areas with a mean number of respondents of 34 people $(\mathrm{SD}=31)$, nested in 387 municipalities (level 3).

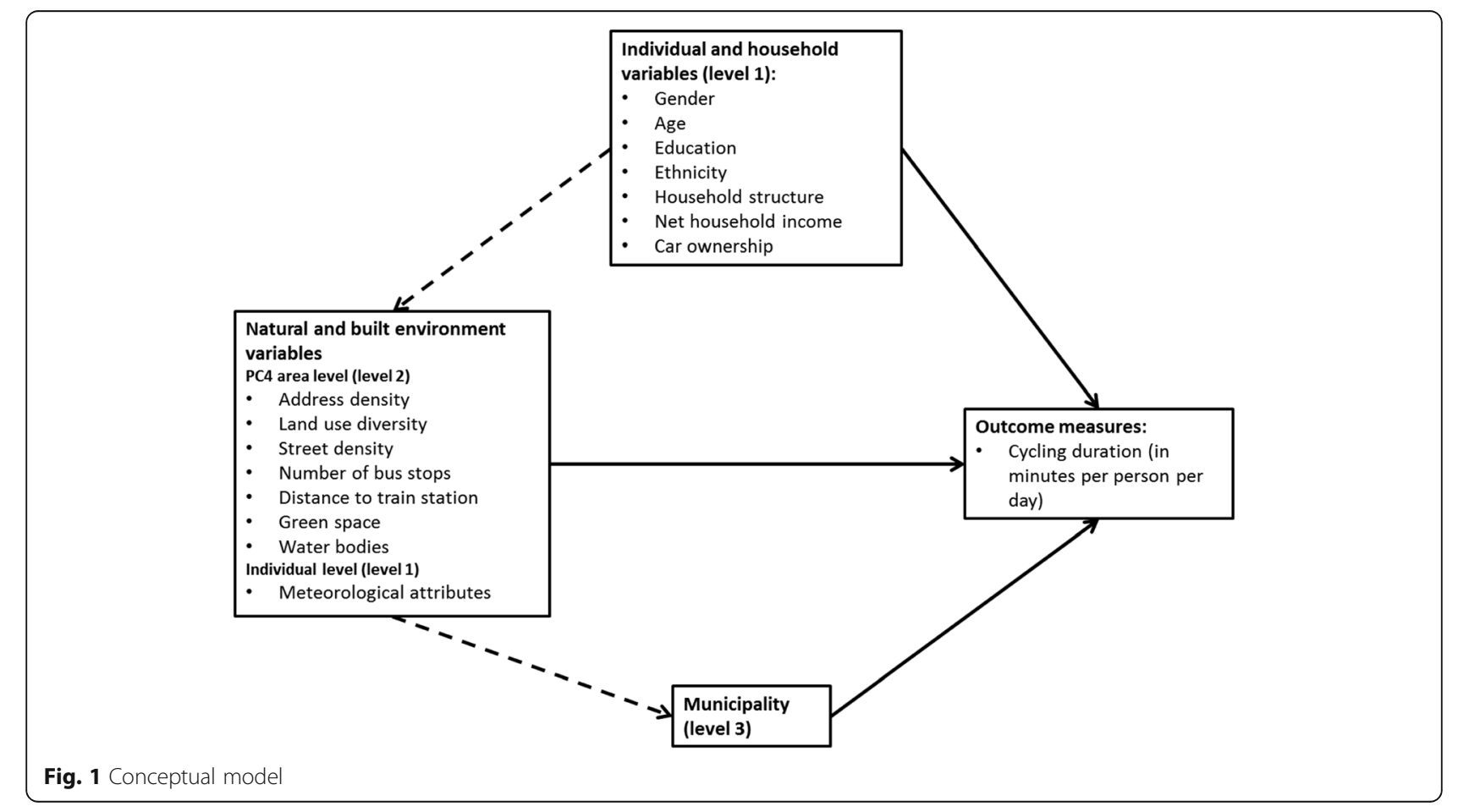




\section{Cycling duration}

The outcome variable was total daily cycling duration in minutes per person. This included cycling for all purposes, i.e. travel-related as well as recreational cycling. Cycling duration was calculated based on the travel dairy data.

\section{Built environment variables}

The selection of built environment measures was guided by the literature $[29,53]$. The variables were calculated at the PC4 level using existing spatial data [54-56] for the year 2014. Address density refers to the total number of addresses divided by the PC4 area [56]. Land-use diversity is represented by a Shannon entropy index. A value of 0 refers to one land use class per area, and a value of 1 refers to an even distribution of all land use types per area [26, 57]. The operationalization considered the five most relevant land use types for residents' daily activities, namely residential, commercial, industrial, and recreational areas, and public services (e.g., police station, hospital) [56]. Street density [58], distance to nearest train station [54], and number of bus stops per PC4 reflect transportation-related built environment measures. The latter also reflects competition between bicycle and public transportation.

Based on the population of each municipality, municipality size was classified into four classes: the four largest cities, which have $>250,000$ inhabitants (i.e., Amsterdam, Rotterdam, Den Haag, and Utrecht); medium-sized cities with 100,000-250,000 inhabitants; small urban areas with 50,000-100,000 inhabitants; and suburban/rural areas with $<50,000$ inhabitants (see Figure 2 in the Appendix 1) [59].

\section{Natural environment variables}

Daily meteorological variables were collected from 33 weather stations across the Netherlands [60]. We obtained weather data from the weather station closest to each participant's residential area for the day on which the travel diary was kept. We matched the trip date with daily measures of maximum air temperature (in ${ }^{\circ} \mathrm{C}$ ), precipitation sum (in $\mathrm{mm}$ ), and average wind speed (in $\mathrm{m} / \mathrm{s}$ ), all of which are frequently used measures $[31,42]$. The proportion of green space (including agricultural and natural areas, man-made greenery (e.g., parks)) and water space per PC4 was abstracted from the most recent Dutch land use database for the year 2012 [61].

\section{Individual and household characteristics}

Individual characteristics were obtained from the National Travel Survey. We categorized net household income per year into low $(<€ 20,000)$, medium $(€ 20,000-40,000)$, and high $(>€ 40,000)$ [62]. Educational attainment was stratified into three categories: low (i.e., primary school and lower general secondary school), medium (i.e., upper-division secondary school), and high (i.e., college and university) [63]. We also controlled for numerous other demographic characteristics, including age, gender, ethnicity, household structure, and car ownership.

\section{Statistical analyses}

Descriptive statistics were used to summarize the data, and Pearson correlation coefficients were used to test for multicollinearity among the covariates. Correlations $<-0.8$ or $>0.8$ are considered problematic [64].

To examine the associations between the built environment variables and cycling duration, we constructed multilevel regression models that allowed variables observed at different hierarchical levels (i.e., individuals nested in PC4 area, nested in municipalities). Unlike basic regressions, multilevel models can capture correlations that arise due to hierarchical data structures [65-67]. Furthermore, as the outcome variable (cycling duration) could not be negative, and showed an excess of zeros due to a relatively large share of respondents not reporting any cycling trips on the day of the survey, wrongly assuming that data were not censored to zero would have led to wrongly predicting a non-existent negative value. We therefore applied a multilevel Tobit regression model, which can better handle the dependent variables' absence of negative values and excess of zero [68]. To facilitate the interpretation of the variance at both PC4 area level and municipality level, we calculated two intraclass correlation coefficients (ICC) [69]. The ICC refers to the proportion of total variance in the outcome that is attributable to the PC4 level and municipality level [70]. For example, the ICC in level 2 expresses the similarity in cycling duration between persons located in the same PC4. An ICC equal to $100 \%$ would imply that all people in a PC4 are have a similar cycling duration, while an ICC equal to $0 \%$ imply that people do not share any PC4 area related cycling duration.

Our multilevel regression models were restricted to random intercepts, because the average cluster size was small (i.e., on average 34 people were nested in each PC4 area and eight PC4 areas were nested in each municipality), resulting in reduced power for both random intercepts and slopes model [71].

We estimated the following models. First, we fitted a three-level random intercept model without explanatory variables (model 1). Second, model 1 was extended with individual and household variables (model 2). Third, model 3 also included both the natural and the built environment variables. Due to varying units, the continuous variables were standardized, 
Table 1 Descriptive statistics

\begin{tabular}{|c|c|c|c|}
\hline \multirow[t]{2}{*}{ Indicators } & \multirow[t]{2}{*}{ Measures } & \multicolumn{2}{|c|}{$\begin{array}{l}\text { All participants } \\
(N=110,027)\end{array}$} \\
\hline & & Mean(S.D.) & $\%$ per category \\
\hline \multicolumn{4}{|l|}{ Dependent variables } \\
\hline Cycling duration (in minutes) & $\geq 0$ min per day & $12.8(32.6)$ & \\
\hline \multicolumn{4}{|l|}{ Individual and household variables } \\
\hline \multirow[t]{2}{*}{ Gender } & Male & & $48.3 \%$ \\
\hline & Female & & $51.7 \%$ \\
\hline \multirow[t]{7}{*}{ Age } & $20-29$ & & $12.8 \%$ \\
\hline & $30-39$ & & $16.0 \%$ \\
\hline & $40-49$ & & $21.5 \%$ \\
\hline & $50-59$ & & $20.8 \%$ \\
\hline & $60-69$ & & $17.1 \%$ \\
\hline & $70-79$ & & $9.1 \%$ \\
\hline & $80-89$ & & $2.7 \%$ \\
\hline \multirow[t]{4}{*}{ Household structure } & Single-person household & & $17.1 \%$ \\
\hline & Couple without children & & $36.8 \%$ \\
\hline & Couple with children & & $40.4 \%$ \\
\hline & Single parent with children & & $4.5 \%$ \\
\hline \multirow[t]{3}{*}{ Net household income } & $<€ 20,000$ & & $13.1 \%$ \\
\hline & $€ 20,000-40,000$ & & $42.8 \%$ \\
\hline & $>€ 40,000$ & & $44.2 \%$ \\
\hline \multirow[t]{3}{*}{ Education } & Low & & $27.4 \%$ \\
\hline & Medium & & $37.6 \%$ \\
\hline & High & & $35.1 \%$ \\
\hline \multirow[t]{2}{*}{ Ethnicity } & Dutch & & $94.4 \%$ \\
\hline & Non-Dutch & & $5.6 \%$ \\
\hline \multirow[t]{3}{*}{ Car ownership } & No car & & $10.8 \%$ \\
\hline & $1 \mathrm{car}$ & & $52.6 \%$ \\
\hline & 2 or more cars & & $36.6 \%$ \\
\hline \multicolumn{4}{|l|}{ Built environment variables } \\
\hline \multicolumn{2}{|l|}{$\begin{array}{l}\text { Address density } \\
\left(1000 \text { addresses per } \mathrm{km}^{2}\right)\end{array}$} & $1.31(1.54)$ & \\
\hline \multicolumn{2}{|l|}{ Land use diversity } & $0.62(0.21)$ & \\
\hline \multicolumn{2}{|l|}{$\begin{array}{l}\text { Street density } \\
\left(\mathrm{km} / \mathrm{km}^{2}\right)\end{array}$} & $16.30(8.83)$ & \\
\hline \multicolumn{2}{|l|}{ Number of bus stops } & $13(10.58)$ & \\
\hline \multicolumn{2}{|l|}{ Distance to train station (km) } & $6.79(7.29)$ & \\
\hline \multicolumn{4}{|l|}{ Natural environment variables } \\
\hline \multicolumn{2}{|l|}{ Green space (\%) } & $61.59(23.34)$ & \\
\hline \multicolumn{2}{|l|}{ Water bodies (\%) } & $4.18(6.52)$ & \\
\hline \multicolumn{2}{|l|}{ Daily max. Air temperature $\left({ }^{\circ} \mathrm{C}\right)$} & $14.6(7.2)$ & \\
\hline \multicolumn{2}{|l|}{ Daily precipitation sum (mm) } & $4.1(1.96)$ & \\
\hline \multicolumn{2}{|l|}{ Daily average wind speed (m/s) } & $2.01(4.33)$ & \\
\hline \multirow{2}{*}{$\begin{array}{l}\text { Percentage of respondents in } \\
\text { each municipality size }\end{array}$} & Four largest cities & & $8.6 \%$ \\
\hline & Medium-sized cities & & $21.3 \%$ \\
\hline
\end{tabular}


Table 1 Descriptive statistics (Continued)

\begin{tabular}{llll}
\hline Indicators & Measures & $\begin{array}{l}\text { All participants } \\
(N=110,027)\end{array}$ & \% per category \\
\cline { 2 - 3 } & & Mean(S.D.) & $17.3 \%$ \\
& Small urban areas & $52.7 \%$ & Suburban/rural areas \\
\hline
\end{tabular}

and the most frequent category was used as the reference category. Subsequently, interactions between environmental factors and municipality size were tested in separate models, by adding the interaction term based on model 2, which resulted in a total of 10 interaction models. Significance was interpreted using the 95\% confidence interval (CI). This interaction approach was based on previous interaction studies [72, 73]. All models were implemented in Stata 15.

\section{Results}

\section{Descriptive statistics}

The sample comprised participants aged from 20 to 89 years, $51.7 \%$ were females. Most people aged 40 49 years $(21.5 \%)$ and $50-59$ years (20.8\%). About $30.4 \%$ of the participants $(n=33,443)$ cycled for more than $1 \mathrm{~min}$ per day, the average daily cycling duration was $42.2 \mathrm{~min}$ per day. Among all participants, the average daily cycling duration was $12.8 \mathrm{~min}$. Also, the variations between PC4 areas were larger (average duration $=11.86 \mathrm{~min}, \mathrm{SD}=10.86)$ than they were between municipalities (average duration $=11.81 \mathrm{~min}$, $\mathrm{SD}=3.77$ ). The longest average cycling duration occurred in Groningen, a municipality in the north of the Netherlands (see Figure 3 in the Appendix 2). Further, descriptive statistics regarding cycling behavior, sociodemographic characteristics, natural and built environment characteristics, and different municipality sizes are presented in Table 1. Multicollinearity among the covariates was not a concern, as indicated by the Pearson correlations (see Table 5 in the Appendix 3).

\section{Multilevel Tobit regression model to explain cycling duration}

As shown in Table 2, associations between individual and household characteristics and cycling duration were all significant (Model 2) and remained significant after taking environmental characteristics into account (Model 3). The variance in cycling duration decreased from $3.5 \%$ (in model 2) to $3.4 \%$ (in model 3 ) at the PC4 area level, indicating that cycling duration variation between PC4 areas could be to a minor extent explained by natural and built environmental characteristics (see Table 2). Rather, an alternative reason for the minor difference could be the actual PC4 areas do not correspond with the boundaries that shape the relevant environment for cycling duration [70]. For municipalities, the variance in cycling duration remained at $2.2 \%$, also after taking environmental characteristics into account.

The results of model 3 suggest that the built environment variables were largely associated with cycling duration, also when individual and household variables were controlled for. Respondents living in PC4 areas with a higher address density, more bus stops, and shorter distance to the nearest train station tended to cycle longer. A higher temperature was also positively related to cycling duration. Wind speed and precipitation as well as percentage of green showed an inverse correlation with cycling duration. No significant associations were found between cycling duration and the other natural and built environment variables, such as land-use diversity, street density, and water bodies.

Ten interactions between natural and built environment and municipality size were significant (Tables 3 and 4). Several associations between environmental characteristics and cycling were weaker in small urban or rural areas than in urbanized areas. Specifically, the positive associations between address density and street density and cycling duration in larger cities were smaller or even negative in small urban areas. This may explain the nonsignificant association between street density and cycling duration when the interaction effects are not considered in model 3. In contrast, the positive association between number of bus stops and cycling duration was weaker in the four largest cities and the medium-sized cities compared to small urban and rural areas. Further, the negative association between distance to train station and cycling duration was strongest in large cities, compared to less urbanized municipalities. More green was inversely related to cycling duration, and this association was most pronounced in the four largest cities.

\section{Discussion}

\section{Key findings}

People living in areas with a high address density, more bus stops, and shorter distance to train station cycled longer. Further, cycling duration was positively 
Table 2 Results of the three-level Tobit regression model for cycling duration

\begin{tabular}{|c|c|c|c|}
\hline & Model 1 (S.E.) & Model 2 (S.E.) & Model 3 (S.E.) \\
\hline Intercept & $-1.80^{* * *}(0.02)$ & $-1.18^{* * *}(0.03)$ & $-1.13^{* * *}(0.04)$ \\
\hline \multicolumn{4}{|l|}{ Individual and household level } \\
\hline \multicolumn{4}{|l|}{ Age (yrs.) } \\
\hline $20-29$ (ref. $=40-49)$ & & $-0.13^{* * *}(0.03)$ & $-0.14^{* * *}(0.03)$ \\
\hline $30-39$ & & $-0.18^{* * *}(0.03)$ & $-0.19^{* * *}(0.03)$ \\
\hline $50-59$ & & $0.20^{* * *}(0.03)$ & $0.20^{* * *}(0.03)$ \\
\hline $60-69$ & & $0.35^{* * *}(0.03)$ & $0.36^{* * *}(0.03)$ \\
\hline $70-79$ & & $0.13^{* * *}(0.04)$ & $0.13^{* * *}(0.04)$ \\
\hline $80-89$ & & $-0.77^{* * *}(0.06)$ & $-0.76^{* * *}(0.06)$ \\
\hline \multicolumn{4}{|l|}{ Gender } \\
\hline Man (ref. = Female) & & $-0.28^{* * *}(0.02)$ & $-0.28^{* * *}(0.02)$ \\
\hline \multicolumn{4}{|l|}{ Education } \\
\hline Lower (ref. = medium) & & $-0.08^{* * *}(0.02)$ & $-0.08^{* * *}(0.02)$ \\
\hline Higher & & $0.19^{* * *}(0.02)$ & $0.18^{* * *}(0.02)$ \\
\hline \multicolumn{4}{|l|}{ Net household income } \\
\hline$<€ 20,000$ (ref. $=>€ 40,000)$ & & $-0.14^{* * *}(0.03)$ & $-0.14^{* * *}(0.03)$ \\
\hline$€ 20,000-40,000$ & & $-0.10^{* * *}(0.02)$ & $-0.10^{* * *}(0.02)$ \\
\hline \multicolumn{4}{|l|}{ Ethnicity } \\
\hline Other (ref. = Dutch) & & $-0.83^{* * *}(0.04)$ & $-0.85^{* * *}(0.04)$ \\
\hline \multicolumn{4}{|l|}{ Household structure } \\
\hline Single-person household (ref. = Couple with children) & & $-0.56^{* * *}(0.03)$ & $-0.57^{* * *}(0.03)$ \\
\hline Couple without children & & $-0.22^{* * *}(0.02)$ & $-0.23^{* * *}(0.02)$ \\
\hline Single parent with children & & $-0.43^{* * *}(0.04)$ & $-0.43^{* * *}(0.04)$ \\
\hline \multicolumn{4}{|l|}{ Car ownership } \\
\hline No car (ref. = 1 car) & & $0.95^{* * *}(0.03)$ & $0.93^{* * *}(0.03)$ \\
\hline 2 or more cars & & $-0.96^{* * *}(0.02)$ & $-0.95^{* * *}(0.02)$ \\
\hline \multicolumn{4}{|l|}{ Daily weather conditions } \\
\hline Daily average wind speed (m/s) & & $-0.08^{* * *}(0.01)$ & $-0.08^{* * *}(0.01)$ \\
\hline Daily max. Air temperature $\left({ }^{\circ} \mathrm{C}\right)$ & & $0.27^{* * *}(0.01)$ & $0.27^{* * *}(0.01)$ \\
\hline Daily precipitation sum (mm) & & $-0.07^{* * *}(0.01)$ & $-0.08^{* * *}(0.01)$ \\
\hline \multicolumn{4}{|l|}{ 4-digit postal code zone level } \\
\hline Address density (1000 addresses per $\mathrm{km}^{2}$ ) & & & $0.09^{* * *}(0.21)$ \\
\hline Land use diversity & & & $-0.01(0.01)$ \\
\hline Street density $\left(\mathrm{km} / \mathrm{km}^{2}\right)$ & & & $-0.02(0.02)$ \\
\hline Number of bus stops & & & $0.02 *(0.01)$ \\
\hline Distance to train station (km) & & & $-0.06^{* *}(0.02)$ \\
\hline Percentage of green (\%) & & & $-0.04(0.02)$ \\
\hline Percentage of water (\%) & & & $-0.02(0.01)$ \\
\hline \multicolumn{4}{|l|}{ Level 1: individual and household } \\
\hline Variance intercept $\sigma_{1}^{2}$ & $5.29(0.05)$ & $4.98(0.04)$ & $4.98(0.04)$ \\
\hline \multicolumn{4}{|l|}{ Level 2: 4-digit postal code } \\
\hline Variance intercept $\sigma_{2}^{2}$ & $0.11(0.01)$ & $0.07(0.01)$ & $0.06(0.01)$ \\
\hline Level 2: ICC & $4.4 \%$ & $3.5 \%$ & $3.4 \%$ \\
\hline
\end{tabular}


Table 2 Results of the three-level Tobit regression model for cycling duration (Continued)

\begin{tabular}{llll}
\hline & Model 1 (S.E.) & Model 2 (S.E.) & Model 3 (S.E.) \\
\hline Variance intercept $\sigma_{3}^{2}$ & $0.14(0.02)$ & $0.11(0.01)$ & $0.11(0.01)$ \\
Level 3: ICC & $2.5 \%$ & $2.2 \%$ & $2.2 \%$ \\
\hline
\end{tabular}

Sig. Codes: ${ }^{*} p \leq 0.050 ;{ }^{* *} p \leq 0.010 ;{ }^{* *} p \leq 0.001$

related to higher temperatures, whereas rain and wind speed were negatively associated with cycling duration. Water bodies did not have a significant relation to cycling duration. Significant interactions of municipality size with built environment characteristics were found. Increased street density and address density appeared to be less cycling-promotive in small urban areas compared to medium or large cities. On the other hand, the positive association between number of bus stops and cycling duration was weaker in the four largest cities and in medium-sized cities compared to small urban and rural areas. This suggests that relations between environmental characteristics and cycling may be dependent on other circumstances (which differ between highly urbanized and less urbanized areas) and are thus context-specific.

\section{Explanation of key findings}

When natural and built environment characteristics were included in the models, the variance of cycling duration between PC4 areas declined slightly, but variations at the municipality level could not be explained by environmental characteristics at all. One plausible reason is that because these built environment variables are measured at the PC4 area level, they are inherently more capable of explaining the variance change at the PC4 level than at the municipality level. Another possible explanation is that the low variability in urban design may be typical of Dutch urban areas. The Netherlands is a high-density country with a very good cycling infrastructure and a flat topography. A Dutch walking study also came up with similar findings [72].

Consistent with previous studies $[39,74]$, an association was found between built environment variables and cycling duration: people living in areas with a high address density, more bus stops, and a shorter distance to a train station cycled longer. This may be because, for example, popular destinations, like the city center also have many bus stops. Likewise, people would also be more likely to undertake cycling activities in the city center. In addition, previous studies found that when the distance between a residence and a train station is $1.5-3.7 \mathrm{~km}$, bicycle use increases [24, 75]. In the Netherlands, active transportation modes like cycling play a key role in access to and egress from public transportation (e.g., bus stops, train stations): Nearly $50 \%$ of all trips between home and train station were conducted by bike [14].

Contrary to previous findings [76], in our study land use diversity was not significantly associated with cycling duration. The contrary evidence suggests that mixed-use development in high-density cities may not always have the expected, positive effect on cycling duration. This may be because a high level of land use diversity is associated with heavy traffic, which might eventually weaken people's motivation to cycle [39]. Also, the non-significant association between street density and cycling duration in this study could be explained by a relatively high level of connectivity, which is in line with previous studies [77]. The percentage of green and water surface was negatively related to cycling duration, which is also in line with other studies $[47,78]$. This negative effect suggests that whereas people living in attractive residential areas (with green and water areas) tend to remain in and around their houses or gardens, people living in less attractive areas, with relatively little green and/or water, report more cycle trips. Another possible explanation is that most direct routes are through areas with less green and water, as most individuals want to get to their destination as quickly and easily as possible [47].

Weather variables were significantly related to cycling duration, which confirms previous Dutch studies [34, 33, 42]. High daily precipitation total and high average wind speed had negative effects on cycling, whereas cyclists were more keen to ride when there were high levels of sunshine and high temperatures, as pleasant weather stimulated cycling for recreation [33].

Most of the built environment characteristics tested had significant main effects on cycling duration, independent of municipality size [79]. A key finding of the present study was that several associations between built environment characteristics and cycling were stronger in urbanized areas than in small urban or rural areas. Specifically, interactions indicated that the association of address density and street density with cycling duration was weaker in small urban areas compared to larger cities. On the other hand, the positive association between number of bus stops and cycling duration was weaker in the four largest cities and the medium-sized cities compared to small urban and 


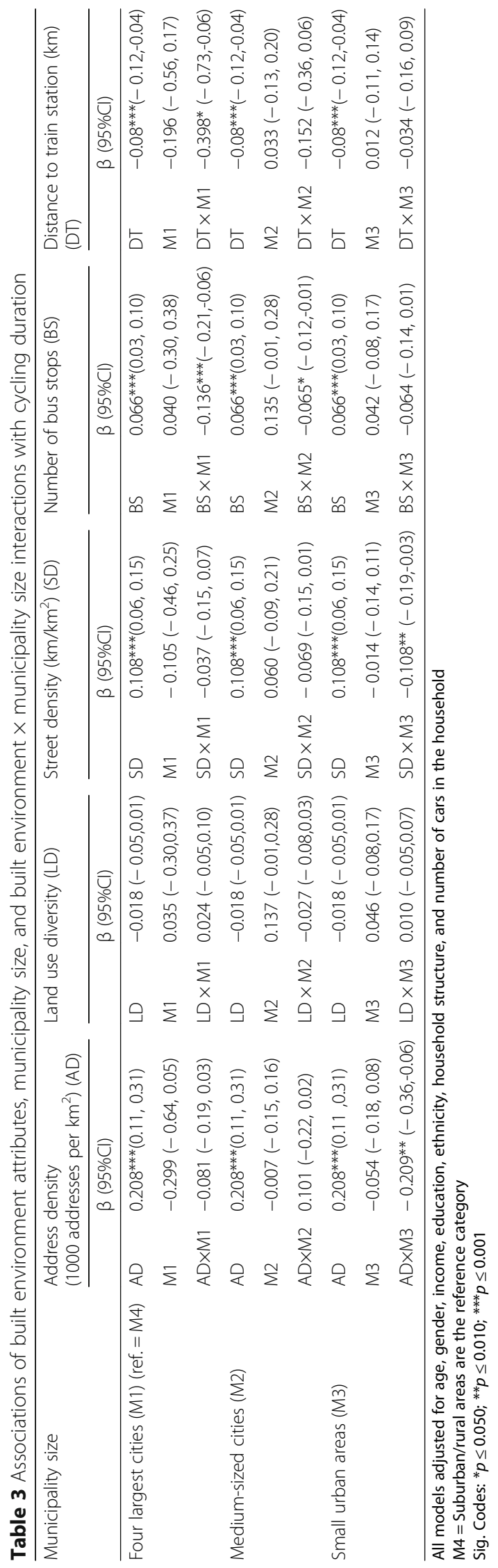




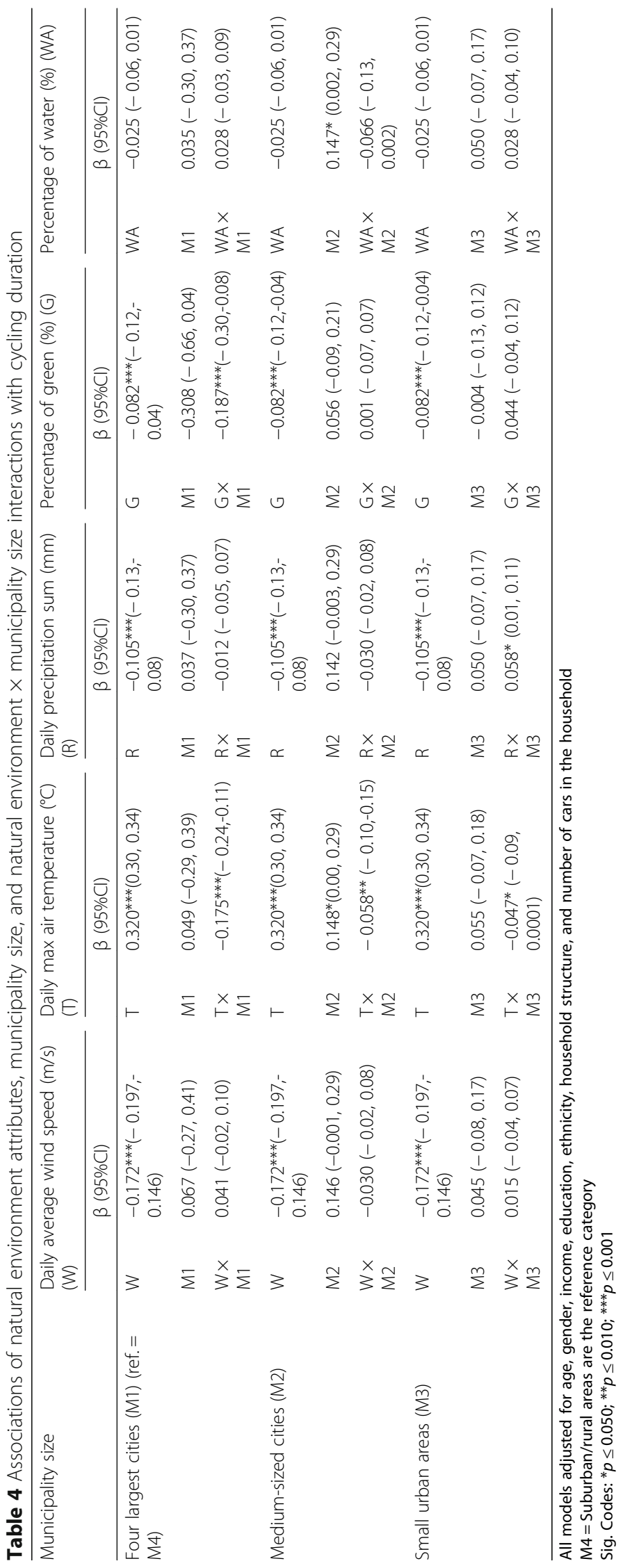


rural areas. One interpretation is that more bus stops means more motorized vehicles on the road, which increases the risk of collisions between bicycles and motorized vehicles, especially in large urban areas [7]. Another possible explanation is that there is competition between public transportation and bicycle use, which is confirmed by previous research [80]. In addition, the negative association between distance to the nearest train station and cycling duration was stronger in the four largest cities, indicating that a shorter distance to the nearest train station encourages people to cycle more. Regarding the daily maximum temperature, the association with cycling duration was weaker in the four largest cities than in rural areas. A possible explanation is that most Dutch cities have a substantial urban heat island (UHI) that is significantly warmer than the surrounding rural areas due to human activities [81].

\section{Strengths and limitations}

The study results need to be interpreted in light of some limitations. First, whereas the NTS data for the period 2010-2014 were used, most built environment variables describe the situation in 2014, and for green space and water bodies we used data from 2012. However, the built environment characteristics used are not expected to have changed much over a couple of years. Second, bicycle use was not separately analyzed in terms of trip purpose. However, associations between natural and built environment characteristics and cycling duration differ by trip purpose [82]. For example, increasing the tree coverage could increase recreational cycling. It would be interesting for future studies to examine cycling duration for different trip purposes separately. Notably, the relationships between natural and built environment characteristics and cycling duration are complex, and the further investigation of those relationships is needed. Also, future studies should consider not only individual or built environment characteristics associated with cycling behavior, but also personal motivation, travel mode preferences, or mental health, which may vary regarding environmental awareness and/or attitudes toward cycling.

This paper has several key strengths. First, as far as we are aware, this is the first study to examine the extent to which natural and built environment characteristics contribute to inter-PC4 area and inter-municipality differences in cycling behavior in a national Dutch context. Also to the best of our knowledge, no previous studies have investigated municipality size as a moderator between built environment and cycling duration. The uniform and good quality data collocation across years for the whole country reduced the bias during the research and increased the potential for generalizing the results. Second, due to recall biases, measuring aspects of natural and built environment subjectively (e.g., self-report methods) may not accurately assess the association between cycling behavior and the actual natural and built environment characteristics [83, 84]. Therefore, in this study, objective measurements of the natural and built environment were made, which could provide an understanding of how the built environment is constructed regarding policy and urban planning. Third, the hierarchical structure of data, ranging from the individual to the municipality level, was taken into account to correct for possible biases and enable an exploration of variables at different data levels [65].

Because we focused on the environmental variability between PC4 areas and municipalities, the within-PC4 variability was not considered. If natural and built environment characteristics were measured at a more fine-grained area level, this could increase the variation and the understanding of individual travel behavior. However, it is also important to understand the between-area variation (both PC4 area and municipality level), as policies are mainly based on between-municipality variances. Nonetheless, we maximized variation in natural and built environment characteristics, by including many different PC areas across the whole of the Netherlands, including urban and rural areas. Finally, the interaction effects may suggest that relations between environmental characteristics and cycling duration are context-specific (i.e., dependent on circumstances that differ between urbanized and suburban/rural areas). Other countries may benefit from examining Dutch transportation policies, in order to determine whether there are opportunities to adopt or adapt some of these within their own transportation policy environment.

\section{Conclusions}

Higher address density, more bus stops, and shorter distance from home to the nearest train station were positively related to cycling duration. In addition, significant interaction effects suggest that municipality size may moderate the association between environmental characteristics and cycling duration. Our findings need to be replicated in other countries to gain more insight into the interplay between environment and municipality size.

\section{Endnotes}

${ }^{1}$ Heerlen: $45.53 \mathrm{~km}^{2}, 1929$ people per $\mathrm{km}^{2}$.

${ }^{2}$ Groningen: $83.75 \mathrm{~km}^{2}, 2572$ people per $\mathrm{km}^{2}$. 


\section{Appendix 1}

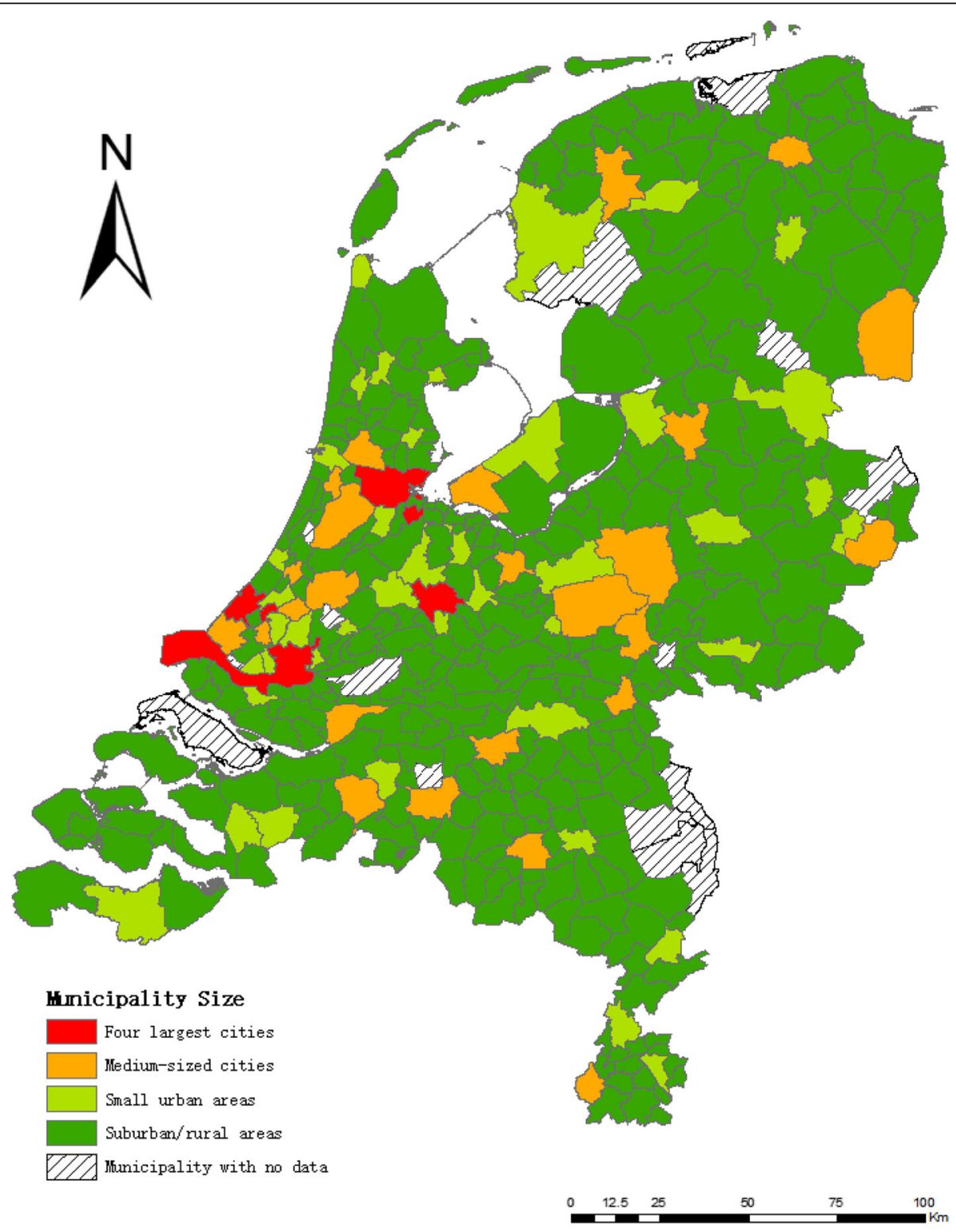

Fig. 2 Distribution of four types of municipality size in the Netherlands. Municipality size was classified into four classes: the four largest cities, which have > 250,000 inhabitants (i.e., Amsterdam, Rotterdam, Den Haag, and Utrecht); medium-sized cities with 100,000-250,000 inhabitants; small urban areas with 50,000-100,000 inhabitants; and suburban/rural areas with <50,000 inhabitants 


\section{Appendix 2}

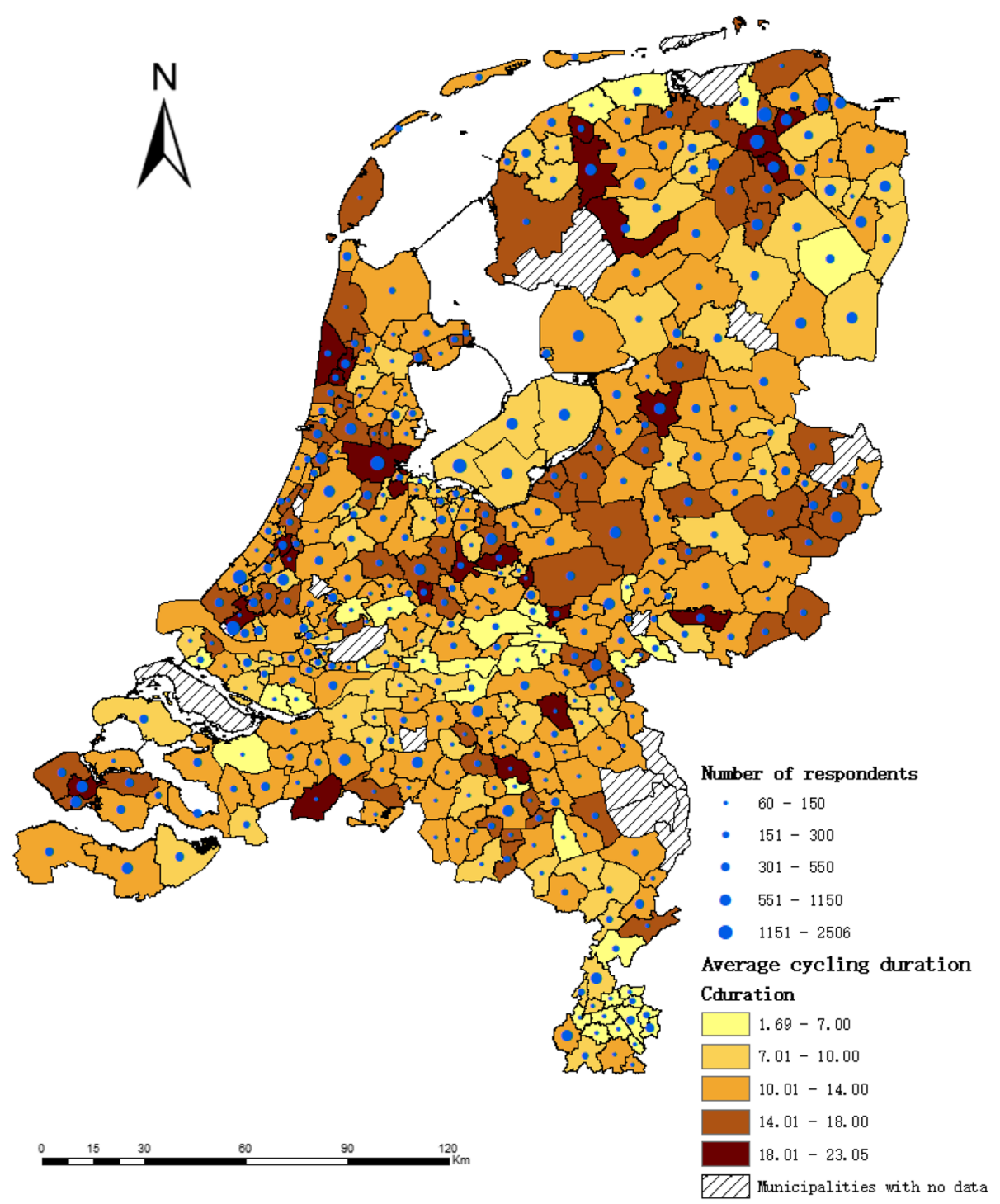

Fig. 3 Distribution of average cycling duration (in minutes) and number of respondents in each municipality. Number of respondents in each PC4 area was represented as different sizes dots. Average cycling duration was presented in minutes

\section{Appendix 3 \\ Test for correlation between built environment variables}

Table 5 Pearson correlation between built environment variables $(N=110,027)$

\begin{tabular}{llllll}
\hline & Address density & Land use diversity & Street density & Number of bus stops & Distance to train station \\
\hline Address density & 1 & $-.150^{* *}$ & $.709^{* *}$ & $.035^{* *}$ & $-.311^{* *}$ \\
Land use diversity & - & 1 & $-.226^{* *}$ & $.103^{* *}$ & $.092^{* *}$ \\
Street density & - & - & 1 & $-.007^{*}$ & $-.371^{* *}$ \\
Number of bus stops & - & - & - & 1 & $-.071^{* *}$ \\
Distance to train station & - & - & - & - & 1 \\
\hline
\end{tabular}

Sig. codes: ${ }^{*} p \leq 0.050 ;{ }^{* *} p \leq 0.010$ 


\section{Abbreviations}

AD: Address density; BS: Number of bus stops; Cl: Confidence interval; DT: Distance to train station; ICC: Intraclass correlation coefficients; LD: Land-use diversity; NTS: National Travel Survey; PC4 areas: 4-digit postal code areas; SD: Street density

\section{Acknowledgements}

The authors thank the Chinese Scholarship Council for providing the Ph.D. scholarship.

\section{Funding}

The present Ph.D. project was funded by the Chinese Scholarship Council (CSC) (201506560001)

\section{Availability of data and materials}

The datasets generated and/or analyzed during the current study are available in the DANS (Data Archiving and Networked Services): https:// easy.dans.knaw.nl.

\section{Authors' contributions}

JG conceived the specific study described in this paper, coordinated the data collection, performed the statistical analyses, and drafted the manuscript. $\mathrm{MH}$, CBMK, and MD provided critical input for the data analyses and helped draft the manuscript. All authors read and approved the final manuscript.

\section{Ethics approval and consent to participate}

The travel survey data are freely available from "DANS" website (the Netherlands institute for permanent access to digital research resources). The data were approved by the Statistics Netherlands Protection Authority.

\section{Consent for publication}

Not applicable.

\section{Competing interests}

The authors declare that they have no competing interests.

\section{Publisher's Note}

Springer Nature remains neutral with regard to jurisdictional claims in published maps and institutional affiliations.

\section{Author details}

'Department of Human Geography and Spatial Planning, Faculty of Geosciences, Utrecht University, Princetonlaan 8a, 3584 CB Utrecht, The Netherlands. ${ }^{2}$ Department of Interdisciplinary Social Science, Faculty of Social and Behavioral Sciences, Utrecht University, Heidelberglaan 1, 3584 CS Utrecht, The Netherlands.

Received: 23 January 2018 Accepted: 17 August 2018 Published online: 29 August 2018

\section{References}

1. Furie $G L$, Desai MM. Active transportation and cardiovascular disease risk factors in U.S. adults. Am J Prev Med. 2012:43(6):621-8.

2. Oja P, Titze S, Bauman A, De Geus B, Krenn P, Reger-Nash B, et al. Health benefits of cycling: a systematic review. Scand J Med Sci Sports. 2011;21(4):496-509.

3. Rutter H, Cavill N, Racioppi F, Dinsdale H, Oja P, Kahlmeier S. Economic impact of reduced mortality due to increased cycling. Am J Prev Med. 2013; 44(1):89-92.

4. Heesch KC, Giles-Corti B, Turrell G. Cycling for transport and recreation: associations with socio-economic position, environmental perceptions, and psychological disposition. Prev Med. 2014;63:29-35.

5. Lee C, Moudon AV. Physical activity and environment research in the health field: implications for urban and transportation planning practice and research J Plan Lit. 2004:19(2):147-81.

6. Mertens L, Compernolle S, Deforche B, Mackenbach JD, Lakerveld J, Brug J, et al. Built environmental correlates of cycling for transport across Europe. Health Place. 2017:44:35-42.

7. Zhao P. The impact of the built environment on bicycle commuting: evidence from Beijing. Urban Stud. 2014;51(5):1019-37.

8. Bauman A, Rissel C, Garrard J, Kerr I, Speidel R, Fishman E. Getting Australia moving: Barriers, facilitators and interventions to get more Australians physically active through cycling. Melbourne: Department of Health and Ageing: 2008. 48 p. Report No:: 6338240.

9. Pucher J, Buehler R. Cycling for everyone: lessons from Europe. Transp Res Rec. 2008;2074:58-65.

10. Bassett DR, Pucher J, Buehler R, Thompson DL, Crouter SE. Walking, cycling, and obesity rates in Europe, North America, and Australia. J Phys Act Health. 2008:5(6):795-814

11. Bonham J, Suh J. Pedalling the city: intra-urban differences in cycling for the journey-to-work. Road Transp Res. 2008;17(4):25-40.

12. Harms $L$, Bertolini $L$, Brömmelstroet MT. Spatial and social variations in cycling patterns in a mature cycling country exploring differences and trends. J Transp Health. 2014;1(4):232-42.

13. Fishman E, Schepers $P$, Kamphuis CBM. Dutch cycling: quantifying the health and related economic benefits. Am J Public Health. 2015;105(8):e13-e5.

14. Schaap N, Harms L, Kansen M, Wust H. Cycling and walking: the grease in our mobility chain. Den Haag: KiM Netherlands Institute for Transport Policy Analysis; 2015. 68 p. ISBN/EAN: 978-90-8902-145-8. Available from: https:// english.kimnet.nl/publications/documenten/2015/10/26/fietsen-en-lopen-desmeerolie-van-onze-mobiliteit-kopie.

15. de Vries SI, Hopman-Rock M, Bakker I, Hirasing RA, van Mechelen W. Built environmental correlates of walking and cycling in dutch urban children: results from the SPACE study. Int J Environ Res Public Health. 2010;7(5): 2309-24.

16. Feng J. The built environment and active travel: evidence from Nanjing, China. Int J Environ Res Public Health. 2016;13(3):301.

17. Handy SL, Boarnet MG, Ewing R, Killingsworth RE. How the built environment affects physical activity: views from urban planning. Am J Prev Med. 2002;23(2 SUPPL. 1):64-73.

18. Sallis JF, Cervero RB, Ascher W, Henderson KA, Kraft MK, Kerr J. An ecological approach to creating active living communities. Annu Rev Public Health. 2006;27:297-322.

19. Buehler R, Pucher J. Cycling to work in 90 large American cities: new evidence on the role of bike paths and lanes. Transportation. 2012;39(2):409-32.

20. Ewing R, Cervero R. Travel and the built environment: a meta-analysis. J Am Plan Assoc. 2010;76(3):265-94.

21. Nielsen TAS, Olafsson AS, Carstensen TA, Skov-Petersen H. Environmental correlates of cycling: evaluating urban form and location effects based on Danish micro-data. Transp Res Part D: Transp Environ. 2013;22:40-4.

22. Zahabi SAH, Chang A, Miranda-Moreno LF, Patterson Z. Exploring the link between the neighborhood typologies, bicycle infrastructure and commuting cycling over time and the potential impact on commuter GHG emissions. Transp Res Part D: Transp Environ. 2016:47:89-103.

23. Wijk DC, Groeniger JO, Lenthe FJ, Kamphuis CB. The role of the built environment in explaining educational inequalities in walking and cycling among adults in the Netherlands. Int J Health Geogr. 2017:16(1):10.

24. Heinen E, van Wee B, Maat K. Commuting by bicycle: an overview of the literature. Transp Rev, 2010:30(1):59-96.

25. Christiansen LB, Cerin E, Badland H, Kerr J, Davey R, Troelsen J, et al. international comparisons of the associations between objective measures of the built environment and transport-related walking and cycling: IPEN adult study. J Transp Health. 2016:3(4):467-78.

26. Helbich M. Children's school commuting in the Netherlands: does it matter how urban form is incorporated in mode choice models? Int J Sustain Transp. 2017;11(7):507-17.

27. Munshi T. Built environment and mode choice relationship for commute trave in the city of Rajkot, India. Transp Res Part D: Transp Environ. 2016:44:239-53.

28. Helbich M, Emmichoven MJZV, Dijst MJ, Kwan MP, Pierik FH, Vries SID. Natural and built environmental exposures on children's active schoo travel: a Dutch global positioning system-based cross-sectional study. Health Place. 2016:39:101-9.

29. Wong BY-M, Faulkner G, Buliung R. GIS measured environmental correlates of active school transport: a systematic review of 14 studies. Int J Behav Nutr Phys Act. 2011:8(1):39.

30. Ewing R, Schroeer W, Greene W. School location and student travel: Analysis of factors affecting mode choice. Transport Res Record. 2004;1895:55-63.

31. Böcker L, Dijst M, Faber J, Helbich M. En-route weather and place valuations for different transport mode users. J Transp Geogr. 2015;47: $128-38$

32. Thomas T, Jaarsma R, Tutert B. Exploring temporal fluctuations of daily cycling demand on Dutch cycle paths: the influence of weather on cycling. Transportation. 2013;40(1):1-22. 
33. Heinen E, Maat K, Van Wee B. Day-to-day choice to commute or not by bicycle. Transport Res Record. 2011;2230:9-18.

34. Böcker $L$, Thorsson $S$. Integrated weather effects on cycling shares, frequencies, and durations in Rotterdam, the Netherlands. Weather Climate Soc. 2014;6(4):468-81.

35. Tucker $P$, Gilliland J. The effect of season and weather on physical activity: a systematic review. Public Health. 2007;121(12):909-22.

36. Parkin J, Wardman M, Page M. Estimation of the determinants of bicycle mode share for the journey to work using census data. Transportation. 2008:35(1):93-109.

37. Zahran S, Brody SD, Maghelal P, Prelog A, Lacy M. Cycling and walking: explaining the spatial distribution of healthy modes of transportation in the United States. Transp Res Part D: Transp Environ. 2008;13(7):462-70.

38. Rodríguez DA, Joo J. The relationship between non-motorized mode choice and the local physical environment. Transp Res Part D: Transp Environ. 2004; 9(2):151-73.

39. Wang Y, Chau CK, Ng WY, Leung TM. A review on the effects of physical built environment attributes on enhancing walking and cycling activity levels within residential neighborhoods. Cities. 2016;50:1-15.

40. Lee C, Moudon AV. Neighbourhood design and physical activity. Build Res Inf. 2008;36(5):395-411.

41. Feuillet T, Charreire H, Menai M, Salze P, Simon C, Dugas J, et al. Spatial heterogeneity of the relationships between environmental characteristics and active commuting: towards a locally varying social ecological model. Int J Health Geogr. 2015;14(1):12.

42. Helbich M, Böcker L, Dijst M. Geographic heterogeneity in cycling under various weather conditions: evidence from greater Rotterdam. J Transp Geogr. 2014;38:38-47.

43. Panter JR, Jones AP, van Sluijs EMF. Environmental determinants of active travel in youth: a review and framework for future research. Int J Behav Nutr Phys Act. 2008:5:34.

44. Goodman A, Sahlqvist S, Ogilvie D. Who uses new walking and cycling infrastructure and how? Longitudinal results from the UK iConnect study. Prev Med. 2013;57(5):518-24.

45. Heesch KC, Sahlqvist S, Garrard J. Gender differences in recreational and transport cycling: a cross-sectional mixed-methods comparison of cycling patterns, motivators, and constraints. Int J Behav Nutr Phys Act. 2012;9:106.

46. Perchoux C, Nazare J-A, Benmarhnia T, Salze P, Feuillet T, Hercberg S, et al. Neighborhood educational disparities in active commuting among women: the effect of distance between the place of residence and the place of work/study (an ACTI-Cités study). BMC Public Health. 2017;17(1):569.

47. Winters M, Brauer M, Setton EM, Teschke K. Built environment influences on healthy transportation choices: bicycling versus driving. J Urban Health. 2010:87(6):969-93.

48. Adams MA, Frank LD, Schipperijn J, Smith G, Chapman J, Christiansen LB, et al. International variation in neighborhood walkability, transit, and recreation environments using geographic information systems: the IPEN adult study. Int J Health Geogr. 2014;13(1):43.

49. Schwanen T, Dieleman FM, Dijst M. Car use in Netherlands daily urban systems: does polycentrism result in lower commute times? Urban Geogr 2003;24(5):410-30

50. Weber J, Kwan M-P. Evaluating the effects of geographic contexts on individual accessibility: a multilevel Approach1. Urban Geogr. 2003; 24(8):647-71.

51. Fraser SD, Lock K. Cycling for transport and public health: a systematic review of the effect of the environment on cycling. Eur J Pub Health. 2011;21(6):738-43.

52. Onderzoeksbeschrijving OViN [Internet]. Statistics Netherlands. 2015 [cited December, 2015]. Available from: http://www.narcis.nl/dataset/RecordID/ oai\%3Aeasy.dans.knaw.nl\%3Aeasy-dataset\%3A61643/id/3/Language/EN/ uquery/OViN/coll/dataset.

53. Winters M, Davidson G, Kao D, Teschke K. Motivators and deterrents of bicycling: comparing influences on decisions to ride. Transportation. 2011; 38(1):153-68.

54. Centraal Bureau voor de Statistiek (CBS). Wijk-en Buurkaart 2014 [Internet]. Hague: Centraal Bureau voor de Statistiek; 2016 [cited 2017 May 17]. Available from: https://www.cbs.nl/nl-nl/dossier/nederland-regionaal/ geografische\%20data/wijk-en-buurtkaart-2014.

55. Centraal Bureau voor de Statistiek (CBS). Bodemgebruik, wijk-en buurtcijfers 2012 [Internet]. Hague: Centraal Bureau voor de Statistiek; 2016 [updated 2016 Mar 3; cited 2017 May 17]. Available from: https://data.overheid.nl/ data/dataset/cbs-bodemgebruik-wijk--en-buurtcijfers-2012.
56. Centraal Bureau voor de Statistiek (CBS). Kerncijfers wijken en buurten 2014 [Key figures neighborhoods in 2014] [Internet]. Hague: Centraal Bureau voor de Statistiek; 2016 [cited 2017 May 20]. Available from: https://data.overheid. nl/data/dataset/cbs-kerncijfers-wijken-en-buurten-2014.

57. Cervero R, Kockelman K. Travel demand and the 3Ds: density, diversity, and design. Transp Res Part D: Transp Environ. 1997;2(3):199-219.

58. Kadaster. Top 10NL [Internet]. Apeldoorn: Kadaster; 2012. [cited 2017 May 20]. Available from: https://www.kadaster.nl/-/top10nl.

59. Centraal Bureau voor de Statistiek (CBS). Gebieden in Nederland 2014 [Internet]. Hague: Centraal Bureau voor de Statistiek; 2014 [updated 2014 Oct 24; cited 2017 May 10]. Available from: http://statline.cbs.nl/Statweb/ publication/?DM=SLNL\&PA=82496NED\&D1 $=51-52 \& D 2=$ $2,8,12,15,23,38,65,106,118,122,157-$ $158,171,179,196,214,233,246,249,258,277,293,311,326 \& W=T$

60. Publically available weather records [Internet]. 2017 [cited 30.05.17]. Available from: http://projects.knmi.nl/klimatologie/metadata/index.html.

61. Hazeu GW, Schuiling C, Dorland GJ van, Roerink GJ, Naeff HSD, Smidt RA. Landelijk Grondgebruiksbestand Nederland versie 7 (LGN7): vervaardiging, nauwkeurigheid en gebruik [Internet]. Wageningen: Alterra Research Institute, Wageningen UR; 2014. 92 p. Report No.: 455946. Available from: http://library.wur.n//WebQuery/wurpubs/455946.

62. Fishman E, Böcker L, Helbich M. Adult active transport in the Netherlands: an analysis of its contribution to physical activity requirements. PLoS One. 2015;10(4):e0121871.

63. Centraal Bureau voor de Statistiek (CBS). Bevolking; onderwijsniveau; geslacht, leeftijd en migratieachtergrond [Internet]. [cited 2016 Feb 16]. Available from: http://statline.cbs.nl/Statweb/selection/?DM=SLNL\&PA= 82275NED\&W=T.

64. Freedman D, Pisani R, Purves R, Adhikari A. Statistics. 2nd ed. New York: Norton; 1991.

65. Stawski RS. Multilevel analysis: an introduction to basic and advanced multilevel modeling. Struct Equ Model Multidiscip J. 2013;20(3):541-50,

66. Bottai M, Salvati N, Orsini N. Multilevel models for analyzing people's daily movement behavior. J Geogr Syst. 2006;8(1):97-108.

67. Jones K, Duncan C. People and places: the multilevel model as a general framework for the quantitative analysis of geographical data. In: Longley $\mathrm{P}$, Batty M, editors. Spatial analysis: Modelling in a GIS environment. New Jersey: Wiley; 1996. p. 79-104.

68. Greene WH. Econometric analysis. 5th ed. Upper Saddle River: Prentice Hall; 2003. p. 1026.

69. Snijders TAB, Bosker RJ. Multilevel analysis: an introduction to basic and advanced multilevel modeling. London: Sage; 1999. p. 266.

70. Merlo J, Chaix B, Yang M, Lynch J, Råstam L. A brief conceptual tutorial of multilevel analysis in social epidemiology: linking the statistical concept of clustering to the idea of contextual phenomenon. J Epidemiol Community Health. 2005;59(6):443-9.

71. Snijders TA. Power and sample size in multilevel linear models. In: Everitt BS, Howell DC, editors. Encyclopedia of statistics in behavioral science. New Jersey: Wiley; 2005. p. 1570-3. Available from: https://onlinelibrary.wiley.com/ doi/book/10.1002/0470013192.bsa492.

72. Beenackers MA, Kamphuis CB, Prins RG, Mackenbach JP, Burdorf A, van Lenthe FJ. Urban form and psychosocial factors: do they interact for leisuretime walking? Med Sci Sports Exerc. 2014;46(2):293-301.

73. Ding D, Sallis JF, Conway TL, Saelens BE, Frank LD, Cain KL, et al. Interactive effects of built environment and psychosocial attributes on physical activity: a test of ecological models. Ann Behav Med. 2012;44(3):365-74.

74. McCormack GR, Shiell A. In search of causality: a systematic review of the relationship between the built environment and physical activity among adults. Int J Behav Nutr Phys Act. 2011;8:125.

75. Givoni $M$, Rietveld $P$. The access journey to the railway station and its role in passengers' satisfaction with rail travel. Transp Policy. 2007;14(5): 357-65.

76. Ding $C$, Lin $Y$, Liu C. Exploring the influence of built environment on tourbased commuter mode choice: a cross-classified multilevel modeling approach. Transp Res Part D: Transp Environ. 2014;32:230-8.

77. Eriksson U, Arvidsson D, Gebel K, Ohlsson H, Sundquist K. Walkability parameters, active transportation and objective physical activity: moderating and mediating effects of motor vehicle ownership in a cross-sectional study. Int J Behav Nutr Phys Act. 2012;9:123.

78. Titze S, Giles-Corti B, Knuiman MW, Pikora TJ, Timperio A, Bull FC, et al. Associations between intrapersonal and neighborhood 
environmental characteristics and cycling for transport and recreation in adults: baseline results from the RESIDE study. J Phys Act Health. 2010;7(4):423-31.

79. Heath GW, Brownson RC, Kruger J, Miles R, Powell KE, Ramsey LT. The effectiveness of urban design and land use and transport policies and practices to increase physical activity: a systematic review. J Phys Act Health. 2006;3(s1):S55-76.

80. Ettema D, Nieuwenhuis R. Residential self-selection and travel behaviour: what are the effects of attitudes, reasons for location choice and the built environment? J Transp Geogr. 2017;59:146-55.

81. Steeneveld G, Koopmans S, Heusinkveld B, Van Hove L, Holtslag A. Quantifying urban heat island effects and human comfort for cities of variable size and urban morphology in the Netherlands. J Geophys Res Atmos. 2011;116(D20129). Available from: https://agupubs.onlinelibrary.wiley. com/doi/abs/10.1029/2011JD015988.

82. Heesch KC, Giles-Corti B, Turrell G. Cycling for transport and recreation: associations with the socio-economic, natural and built environment. Health Place. 2015;36:152-61.

83. Kamphuis CBM, Giskes K, Kavanagh AM, Thornton LE, Thomas LR, van Lenthe FJ, et al. Area variation in recreational cycling in Melbourne: a compositional or contextual effect? J Epidemiol Community Health. 2008; 62(10):890-8.

84. Zhou R, Li Y, Umezaki M, Ding Y, Jiang H, Comber A, et al. Association between physical activity and neighborhood environment among middleaged adults in shanghai. J Environ Public Health. 2013;2013(239595). Available from: https://www.ncbi.nlm.nih.gov/pmc/articles/PMC3652159/. https://doi.org/10.1155/2013/239595.

Ready to submit your research? Choose BMC and benefit from:

- fast, convenient online submission

- thorough peer review by experienced researchers in your field

- rapid publication on acceptance

- support for research data, including large and complex data types

- gold Open Access which fosters wider collaboration and increased citations

- maximum visibility for your research: over $100 \mathrm{M}$ website views per year

At $\mathrm{BMC}$, research is always in progress.

Learn more biomedcentral.com/submissions 